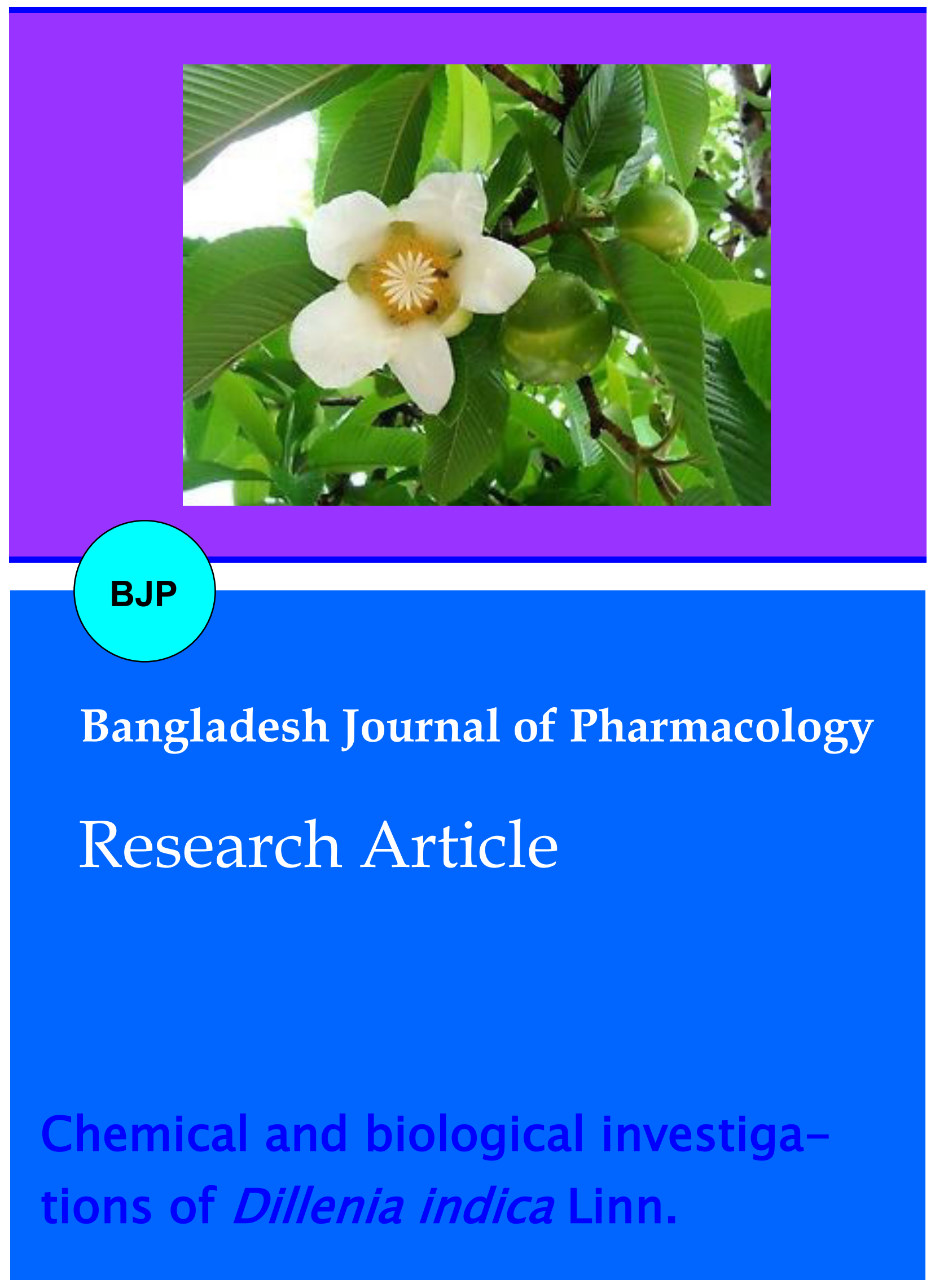


Abstracted/indexed in Academic Search Complete, Agroforestry Abstracts, Asia Journals Online, Bangladesh Journals Online, Biological Abstracts, BIOSIS Previews, CAB Abstracts, Current Abstracts, Directory of Open Access Journals, EMBASE/Excerpta Medica, Google Scholar, HINARI (WHO), International Pharmaceutical Abstracts, Open J-gate, Science Citation Index Expanded and Social Sciences Citation Index

ISSN: $1991-0088$

\title{
Chemical and biological investigations of Dillenia indica Linn.
}

\author{
Most. Nazma Parvin'1, Mohammad S. Rahman², Mohammad S. Islam¹ and \\ Mohammad A. Rashid²
}

${ }^{1}$ Department of Clinical Pharmacy and Pharmacology, Faculty of Pharmacy, University of Dhaka, Dhaka 1000; ${ }^{2}$ Department of Pharmaceutical Chemistry, Faculty of Pharmacy, University of Dhaka, Dhaka 1000, Bangladesh.

\begin{tabular}{|c|c|}
\hline \multicolumn{2}{|l|}{ Article Info } \\
\hline Received: & 29 June 2009 \\
\hline Accepted: & 30 June 2009 \\
\hline Available Online: & 2 July 2009 \\
\hline \multicolumn{2}{|c|}{ DOI: 10.3329/bjp.v4i2.2758 } \\
\hline \multicolumn{2}{|c|}{$\begin{array}{l}\text { Cite this article: } \\
\text { Parvin MN, Rahman MS, Islam MS, } \\
\text { Rashid MA. Chemical and biological } \\
\text { investigations of Dillenia indica Linn. } \\
\text { Bangladesh J Pharmacol. 2009; } 4: 122 \\
25 .\end{array}$} \\
\hline
\end{tabular}

\begin{abstract}
A total of four compounds namely, lupeol (1), betulinaldehyde (2), betulinic acid (3) and stigmasterol (4) were isolated from the stem extract of Dillenia indica Linn. The structures of the isolated compounds (1-4) were established by extensive spectroscopic studies. The crude methanolic extracts and its $\mathrm{n}$ hexane, carbon tetrachloride, dichloromethane and chloroform soluble partitionates demonstrated weak antimicrobial activity against a wide range of Gram-positive and Gram-negative bacteria and fungi. The extractives revealed significant cytotoxic activity when tested by brine shrimp lethality bioassay. In addition, the extractives exhibited significant free radical scavenging activity when compared with ascorbic acid.
\end{abstract}

\section{Introduction}

Dillenia indica Linn. (Syn. P. lanigerum; chalta in Bangla; Family-Dilleniaceae) is a evergreen large shrub or small to medium-sized tree that grows all over the Bangladesh. It is reputed as a cooling beverage in fever, expectorant in cough mixture, tonic, laxative and astringent (Maniruzzaman, 1993). Previous phytochemical studies with $D$. indica species revealed the occurrences of a number of triterpenes (Banerji et al., 1975), flavanoids (Pavanasasivam et al., 1975). We, herein, report the isolation of lupeol (1), betulinaldehyde (2), betulinic acid (3) and stigmasterol (4) as well as the antimicrobial activity, cytotoxicity and anti-oxidant activity of extracts from $D$. indica.

\section{Materials and Methods \\ General experimental procedure}

${ }^{1} \mathrm{H}$ spectra were acquired using the Ultra Shield Bruker DPX 400 NMR instrument, and the chemical shifts are reported in ppm with respect to TMS or residual non deutarated solvent signal.

\section{Plant material}

The stems of $D$. indica were collected from Rangpur district in the month of March 2007. The plant was identified by Dr. Mahbuba Khanum, Bangladesh National Herbarium, Dhaka, where a voucher specimen has been deposited (DACB Accession no. 32532). The stems were first sun dried and then ground into a coarse powder using a grinding machine.

\section{Extraction and isolation}

The air-dried and powdered plant material $(1 \mathrm{~kg})$ was extracted with methanol. The extractive was filtered through fresh cotton bed and finally with Whatman No. 1 filter paper. The filtrates were concentrated with a rotary evaporator at low temperature $\left(40-50^{\circ} \mathrm{C}\right)$ and reduced pressure to pro-vide crude methanol extract (7 g). The crude extract (5 g) was partitioned with $n$ hexane, carbon tetrachloride, dichloromethane and chloroform, respectively. The subsequent evaporation of solvents afforded $n$-hexane (1.5 g), carbon tetrachloride $(1.5 \mathrm{~g})$, dichloromethane $(0.6 \mathrm{~g})$ and aqueous soluble $(1.1 \mathrm{~g})$ materials.

The $n$-hexane soluble materials were fractionated by vacuum liquid chromatography. The column was elu- 
ted with petroleum ether, ethyl acetate and methanol mixtures of increasing polarities to provide 28 fractions (50 mL each). Compounds 1 (10 mg) and 2 (30 mg) were obtained as colorless crystals from the fraction eluted with 50 and $10 \%$ ethyl acetate in petroleum ether, respectively. The dichloromethane soluble materials of methanolic extract were fractionated by gel permeation chromatography over sephadex LH 20. The column was eluted with $n$-hexane : dichloromethane : methanol (2:5:1) mixtures to provide 24 fractions (5 $\mathrm{mL}$ each). Com-pound 3 (10 mg) was found as amorphous powder from fractions 14-16.

Evaporation of solvents from the vacuum liquid chromatographic fraction of $n$-hexane soluble materials eluted with $15 \%$ ethyl acetate in petroleum ether gave compound 4 (30 $\mathrm{mg})$ as white mass.

Lupeol (1): colorless crystals; ${ }^{1} \mathrm{H}$ NMR (400 MHz, $\left.\mathrm{CDCl}_{3}\right): \delta 4.74\left(1 \mathrm{H}\right.$, br. s, $\left.\mathrm{H}_{\mathrm{a}}-29\right), 4.61\left(1 \mathrm{H}_{\mathrm{b}}\right.$, br. s, H-29), $3.19(1 \mathrm{H}, \mathrm{dd}, J=11.2,4.8 \mathrm{~Hz}, \mathrm{H}-3), 1.69$ (3H, s , Me-30), 0.98 (3H, s, Me -26), 0.97 (3H, s, Me -23), 0.94 (3H, s, Me -27), 0.82 (3H, s, Me -25), 0.76 (3H, s, Me -24).

Betulinaldehyde (2): colorless crystals; ${ }^{1} \mathrm{H}$ NMR (400 $\left.\mathrm{MHz} \mathrm{CDCl}_{3}\right)$ : $\delta 9.67(1 \mathrm{H}, \mathrm{s}, \mathrm{CHO}), 4.74\left(1 \mathrm{H}\right.$, br. s, $\mathrm{H}_{\mathrm{a}}-$ 29), 4.62 (1H, br. s, $\left.\mathrm{H}_{\mathrm{b}}-29\right), 3.18(1 \mathrm{H}, \mathrm{dd}, J=11.0,4.8 \mathrm{~Hz}$, H-3), 2.85 (1H, m, H-19), 1.69 (3H, s, Me -30), 0.97 (3H, s, Me -26), 0.95 (3H, s, Me -23), 0.91 (3H, s, Me -27), 0.81 (3H, s, Me -25), 0.74 (3H, s, Me -24).

Betulinic acid (3): white mass; ${ }^{1} \mathrm{H}$ NMR (400 MHz, $\left.\mathrm{CDCl}_{3}\right)$ : $\delta 4.73\left(1 \mathrm{H}\right.$, br. s, $\left.\mathrm{H}_{\mathrm{a}}-29\right), 4.60\left(1 \mathrm{H}\right.$, br. s, $\left.\mathrm{H}_{\mathrm{b}}-29\right)$, $3.18(1 \mathrm{H}, \mathrm{dd}, J=11.2,4.9 \mathrm{~Hz}, \mathrm{H}-3), 2.98(1 \mathrm{H}, \mathrm{m}, \mathrm{H}-19)$, $1.68(3 \mathrm{H}, \mathrm{s}, \mathrm{Me}-30), 0.97(3 \mathrm{H}, \mathrm{s}, \mathrm{Me}-26), 0.96(3 \mathrm{H}, \mathrm{s}, \mathrm{Me}$ -23), 0.93 (3H, s, Me -27), $0.81(3 \mathrm{H}, \mathrm{s}, \mathrm{Me}-25), 0.74(3 \mathrm{H}$, $\mathrm{s}, \mathrm{Me}-24)$.

Stigmasterol (4): amorphous powder; ${ }^{1} \mathrm{H}$ NMR data was in close agreement to published data (Khan, R.I. 1991).

\section{Antimicrobial screening}

The disc diffusion method (Radovanović et al., 2009) was used to test antimicrobial activity against thirteen bacteria and three fungi. Solutions of known concentration $(\mu \mathrm{g} / \mathrm{mL})$ of the test samples were made by dissolving measured amount of the samples in calculated volume of solvents (chloroform on methanol). Dried and sterilized filter paper discs (7 $\mathrm{mm}$ diameter) were then impregnated with known amounts of the test substances using micropipette. Discs containing the test material were placed on nutrient agar medium uniformly seeded with the test microorganisms. Standard antibiotic (Kanamycin) discs and blank discs (impregnated with solvents) were used as positive and negative control, respectively. These plates were then kept at low temperature $\left(4^{\circ} \mathrm{C}\right)$ for 24 hours to allow maximum diffusion. The plates were then incubated at $37^{\circ} \mathrm{C}$ for 24 hours to allow maximum growth of the organisms. The antimicrobial activity of the test agent was determined by measuring the diameter of zone of inhibition expre- ssed in millimeter. The experiment was carried out in triplicate and the mean of the readings were taken.

\section{Cytotoxic activity}

For cytotoxicity screening, DMSO solutions of the plant extractives were applied against Artemia salina in a 1day in vivo assay, the experimental details of which could be found elsewhere (Eloff et al., 2008). For the experiment, $4 \mathrm{mg}$ of each of the extracts was dissolved in DMSO. Solutions of varying concentrations such as $400,200,100,50,25,12.5,6.3,3.1,1.6,0.8 \mu \mathrm{g} / \mathrm{mL}$ were obtained by serial dilution technique. The median lethal concentration $\mathrm{LC}_{50}$ of the test samples after 24 hours was obtained by a plot of percentage of the shrimps killed against the logarithm of the sample concentration.

\section{Anti-oxidant activity}

The anti-oxidant activity (free radical scavenging activity) of the extracts on the stable radical 1,1-diphenyl-2 -picrylhydrazyl (DPPH) was determined by the method of Brand-Williams et al., 1995. In the experiment, $2.0 \mathrm{mg}$ of each of the extracts was dissolved in methanol. Solution of varying concentrations such as 500, 250, 125, $62.5,31.3,15.6,7.8,3.9,2.0$ and $1.0 \mu \mathrm{g} / \mathrm{mL}$ were obtained by serial dilution technique. $2 \mathrm{~mL}$ of a methanol solution of the extract of each concentration was mixed with $4 \mathrm{~mL}$ of a DPPH-methanol solution $(20 \mathrm{mg} / \mathrm{L})$ and allowed to stand for $20 \mathrm{~min}$ for the reaction to occur. Then the absorbance was determined at $517 \mathrm{~nm}$ and from these values, the corresponding percentage of inhibitions were calculated by using the following equation:

$\%$ inhibition $=\left[1-\left(\mathrm{ABS}_{\text {sample }} / \mathrm{ABS}_{\text {control }}\right)\right] \times 100$

Then $\%$ inhibitions were plotted against respective concentrations used and from the graph the $\mathrm{IC}_{50}$ was calculated. Ascorbic acid, a potential anti-oxidant, was used as positive control.

\section{Results and Discussion}

Repeated chromatographic separation and purification of the $n$-hexane and dichloromethane soluble partitionates of methanolic extracts of the stem of $D$. indica provided a total of four compounds (1-4), the structures of which were determined by extensive NMR spectral analysis.

The ${ }^{1} \mathrm{H}$ NMR spectrum $\left(400 \mathrm{MHz}, \mathrm{CDCl}_{3}\right.$ ) of compound 1 showed one double doublet of one proton intensity at $\delta 3.19(J=11.2,4.8 \mathrm{~Hz})$ typical for H-3 of a triterpene type carbon skeleton. The spectrum displayed two singlets at $\delta 4.74$ and $\delta 4.61(1 \mathrm{H}$ each) assignable to protons at C-29. A multiplet of one proton intensity at $\delta$ 2.36 was assigned to $\mathrm{H}-19$. The spectrum also displayed six singlets at $\delta 0.76,0.82,0.94,0.97,0.98$, and 1.69 ( $3 \mathrm{H}$ each) assignable to protons of methyl groups at $\mathrm{C}-4$ $\left(\mathrm{H}_{3}-23, \mathrm{H}_{3}-24\right)$, C-10 ( $\left.\mathrm{H}_{3}-25\right), \mathrm{C}-8\left(\mathrm{H}_{3}-26\right), \mathrm{C}-14\left(\mathrm{H}_{3}-27\right)$, 


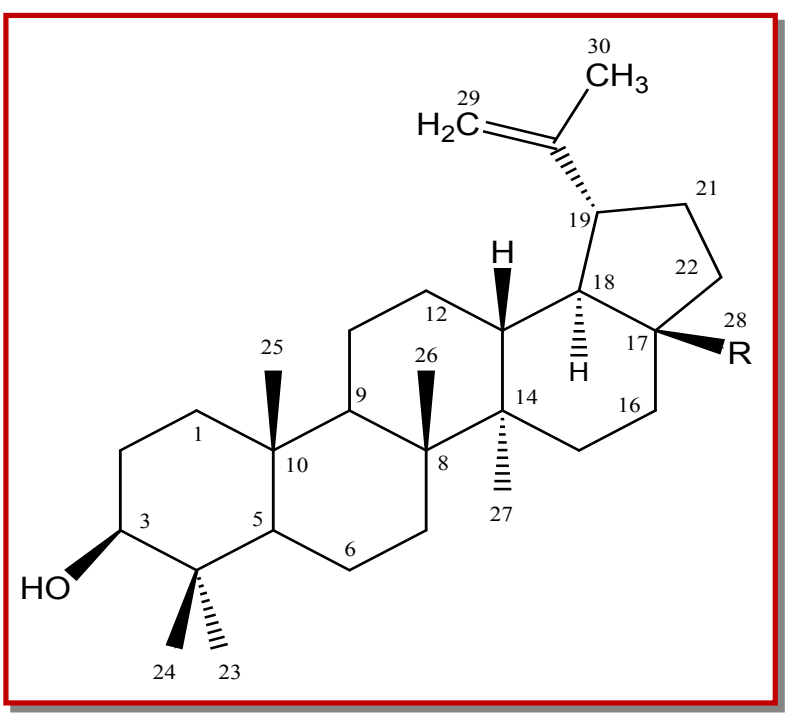

Figure 1: Chemical structure of lupeol $(\mathrm{R}=-\mathrm{H})$, betulinaldehyde $(\mathrm{R}=$ $\mathrm{CHO})$ and betulinic acid $(\mathrm{R}=-\mathrm{COOH})$

and C-20 $\left(\mathrm{H}_{3}-30\right)$, respectively. By comparing the ${ }^{1} \mathrm{H}$ NMR data of compound $\mathbf{1}$ with that of previously published values (Aratanechemuge et al., 2004; Bhattacharyya and Barros, 1985) as well as by co-TLC with authentic sample established its identity as lupeol.

In the ${ }^{1} \mathrm{H}$ NMR spectrum of compound 2 again, the presence of a lupene skeleton having an angular aldehyde group was evident. The spectrum displayed signals attributable to an exomethylene protons at $\delta 4.62$ and $4.74(1 \mathrm{H}$, each, br.s) which together with an allylic methyl at $\delta 1.69$ demonstrated an isopropenyl moiety. The ${ }^{1} \mathrm{H}$ NMR spectrum also showed singlets at $\delta 0.74$, $0.81,0.91,0.95$ and $0.97(3 \mathrm{H}$, each) suggestive of the presence of five methyl groups in this compound. These were attributed to $\mathrm{H}_{3}-25, \mathrm{H}_{3}-27, \mathrm{H}_{3}-26, \mathrm{H}_{3}-23$ and $\mathrm{H}_{3}-24$ (Me-10, Me-14, Me-8, Me-14 and Me-4), respectively. The double doublet $(J=11.0,4.8 \mathrm{~Hz})$ centered at $\delta 3.17$ could be assigned to the oxymethyline proton at C-3. The large coupling of this proton $(\mathrm{H}-3)$ with the vicinyl methylene protons suggested a $\beta$ orientation of the hydroxyl group at C-3. In addition, the spectrum also showed a multiplet at $\delta 2.85$ for the methine proton at $C$ -19 . On the basis of the above spectral features, compound 2 was identified as betulinaldehyde, the identity of which was established by co-TLC with authentic sample as well as by comparison of these data with those reported for betulinaldehyde (Zong et al., 1984).

The ${ }^{1} \mathrm{H}$ NMR spectrum of compound 3 revealed the presence of a lupene type carbon skeleton. It displayed signals attributable to an exomethylene group at $\delta 4.60$ and $4.73(1 \mathrm{H}$, each, br.s) which together with an allylic methyl at $\delta 1.68$ which indicated an isopropenyl function. The double doublet $\delta 3.18$ with couplings of 11.2 and $4.9 \mathrm{~Hz}$ centered at could be assigned to $\mathrm{H}-3$. The large coupling of this proton ( $\mathrm{H}-3)$ with the vicinyl methylene protons suggested a $\beta$ orientation of the

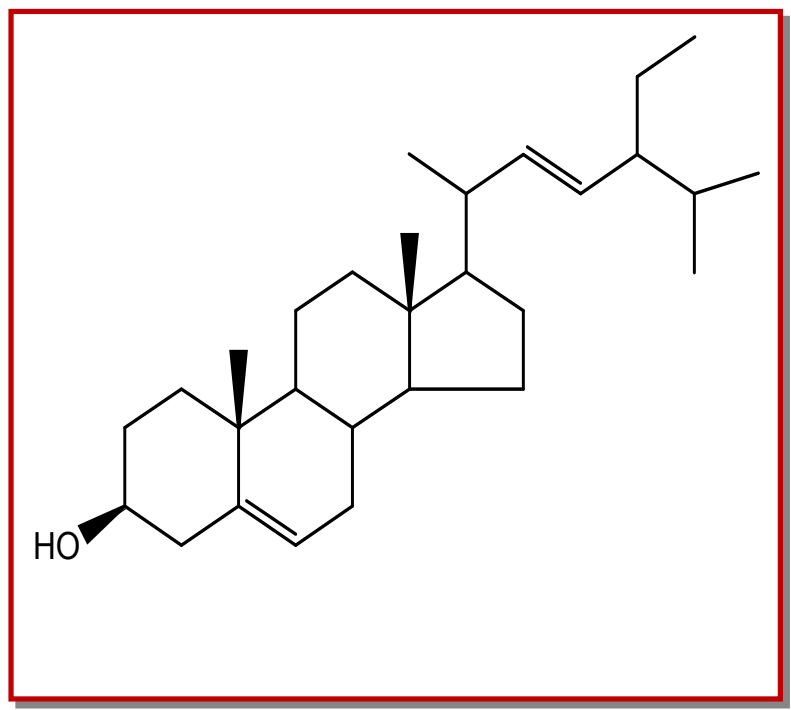

Figure 2: Chemical structure of stigmasterol

hydroxyl group at C-3. In addition, the spectrum also showed a multiplet at $\delta 2.98$ for the methine proton at $C$ -19 and five methyl group resonances at 0.74, 0.81, 0.93, 0.96 and 0.97 . On the basis of the above spectral features, compound 3 was identified as betulinic acid. The identity of 3 as betulinic acid was confirmed by comparison of these data with published values (Ikuta and Itokawa, 1988) as well as by co-TLC with an authentic sample.

The ${ }^{1} \mathrm{H}$ NMR spectrum of compound 4 was almost identical to that recorded for stigmasterol (Panda et al., 2009). This allay with co-TLC with authentic sample confirmed its identity as stigmasterol.

The crude methanol extract and its $n$-hexane, carbon tetrachloride and chloroform soluble fractions $(500 \mu \mathrm{g} /$ disc) were screened against 13 test bacteria (Bacillus cereus, B. megaterium, B. subtilis, Staphylococcus aureus, Sarcina lutea, Escherichia coli, Pseudomonas aeruginosa, Salmonella paratyphi, S. typhi, Shigella boydii, $S$. dysenteriae, Vibrio mimicus, V. parahemolyticus) and 3 fungi (Candida albicans, Aspergillus niger, Sacharomyces cerevacae). Only chloroform soluble extractive showed very weak antimicrobial activity (data not shown).

The extractives were also subjected to brine shrimp lethality bioassay (Table I). In the study, the crude methanolic extract and dichloromethane soluble fractions were found to be highly toxic to brine shrimp nauplii, with $\mathrm{LC}_{50}$ of $8.92 \mu \mathrm{g} / \mathrm{mL}$ and $2.38 \mu \mathrm{g} / \mathrm{mL}$, respectively. This indicated the presence of cytotoxic principles in these extractives.

Although the extractives showed strong cytotoxicity against brine shrimp nauplii, none of them demonstrated significant inhibition of growth of the test microorganisms. This was probably due to the development of partial or complete resistance of the micro- 
Table I

$\mathrm{LC}_{50}$ data of different extracts $D$. indica using brine shrimp lethality bioassay

\begin{tabular}{|lr|}
\hline \multicolumn{1}{|c|}{ Samples } & $\mathrm{LC}_{50}(\mathrm{mg} / \mathrm{mL})$ \\
\hline Vincristine sulphate (standard) & $0.8 \pm 0.5$ \\
Crude methanolic extract & $8.9 \pm 0.6$ \\
$n$-Hexane soluble fraction of the meth- & $11.3 \pm 0.3$ \\
anolic extract & $14.0 \pm 0.4$ \\
$\begin{array}{l}\text { Carbon tetrachloride soluble fraction of } \\
\text { the methanolic extract }\end{array}$ & $2.4 \pm 0.3$ \\
$\begin{array}{l}\text { Dichloromethane soluble fraction of the } \\
\text { methanolic extract }\end{array}$ & $29.1 \pm 0.2$ \\
$\begin{array}{l}\text { Aqueous fraction of the methanolic ex- } \\
\text { tract } \\
\text { The values of } \mathrm{LC}_{50} \text { are expressed as mean } \pm \mathrm{SD}(\mathrm{n}=3)\end{array}$ \\
\hline
\end{tabular}

Table II

\section{Anti-oxidant screening of different extracts of $D$. indica}

\begin{tabular}{|lr|}
\hline Samples & $\mathrm{IC}_{50}(\mathrm{mg} / \mathrm{mL})$ \\
\hline $\begin{array}{l}\text { Ascorbic acid (Standard) } \\
\text { Crude methanolic extract } \\
n \text {-Hexane soluble fraction of the meth- } \\
\text { anolic extract }\end{array}$ & $2.4 \pm 0.2$ \\
$\begin{array}{l}\text { Carbon tetrachloride soluble fraction of } \\
\text { the methanolic extract }\end{array}$ & $4.6 \pm 0.2$ \\
$\begin{array}{l}\text { Dichloromethane soluble fraction of the } \\
\text { methanolic extract }\end{array}$ & $611.6 \pm 0.3$ \\
$\begin{array}{l}\text { Aqueous fraction of the methanolic ex- } \\
\text { tract }\end{array}$ & $84.5 \pm 0.3$ \\
The values of $\mathrm{IC}_{50}$ are expressed as mean $\pm \mathrm{SD}(\mathrm{n}=3)$
\end{tabular}

organisms against the test samples, which might be the result of the indiscriminate use of antibacterial agents.

In case of anti-oxidant screening (Table II), the crude methanolic extract showed very strong free radical scavenging activity with $\mathrm{IC}_{50}$ value of $4.6 \mu \mathrm{g} / \mathrm{mL}$, whereas the aqueous and dichloromethane soluble fractions revealed the $\mathrm{IC}_{50}$ of 84.5 and $162.7 \mu \mathrm{g} / \mathrm{mL}$, respectively, suggestive of moderate anti-oxidant activity. The presence of strong free radical scavenging principles in the crude extractive but not in its Kupchan fractions demonstrated that the anti-oxidant activity of the crude extract might be due to the synergistic activity of the active principles present in the Kupchan fractions.

\section{Acknowledgement}

We wish to thank the Centre for Biomedical Research, University of Dhaka, Bangladesh for providing some laboratory facilities for carrying out the research.

\section{References}

Aratanechemuge Y, Hibasami H, Sanpin K, Katsuzaki H, Kunio IK, Komiya T. Induction of apoptosis by lupeol isolated from mokumen (Gossampinus malabarica L. Merr) in human promyelotic leukemia HL-60 cells. Oncol Rep. 2004; 11: 289-92.

Banerji N, Majumbder P, Dutta NI. A new pentacyclic triterpene lactone from Dillenia indica. Phytochemistry 1975; 14: $1447-48$

Bhattacharyya J, Barros CB. Triterpenoids of Cnidosculus urens. Phytochemistry 1985; 25: 274-76.

Brand-Williams W, Cuvelier ME, Berset C. Use of a free radical method to evaluate anti-oxidant activity. Lebensm. Wiss. Technol. 1995; 28: 25-30.

Eloff JN, Katerere DR, McGaw LJ. The biological activity and chemistry of the southern African Combretaceae. J Ethnopharmacol. 2008; 119: 686-99.

F. M. Maniruzzaman, Udvid Samhita (A compendium of plants in Bangladesh). 1'st ed. Dhaka, Bangla Academy, 1993, p 270.

Ikuta A, Itokawa H. Triterpenoids of Paeonia japonica callus tissue. Phytochemistry 1988; 27: 2813-15.

Panda S, Jafri M, Kar A, Meheta BK, Thyroid inhibitory, antiperoxidative and hypoglycemic effects of stigmasterol isolated from Butea monosperma. Fitoterapia 2009; 80: 123-26.

Pavanasasivam G, Sultanbawa MUS. Chemical investigation of ceylonese plants. Part XII. (+)-3,4',5,7-Tetrahydroxy-3'methoxyflavanone [(+)-dihydroisorhamnetin] and 3,5,7trihydroxy-3', $4^{\prime}$-dimethoxyflavone (dillenetin): Two new natural products from Dillenia indica L. J. Chem. Soc., Perkin Trans. 1 1975; 6: 612-13.

Radovanović A, Radovanović BB, Jovančićević B. Free radical scavenging and antibacterial activities of southern Serbian red wines. Food Chem. 2009; 117: 326-31.

Zhong S, Waterman PG, Jeffreys JAD. Naphthoquinones and triterpenes from African Diospyros species. Phytochemistry 1984; 23: 1067-72.

Author Info

I Mohammad A. Rashid (Principal contact)

I e-mail: rashidma@univdhaka.edu 